\title{
Jeotermal kaynak sularının ahşabın hacimsel daralma ve genişleme özelliklerine karşı önleyici etkinliği
}

\author{
Ahmet Ali Vara,* (D), Aykut Yalçındağ $\breve{b}^{\mathrm{b}}$
}

\begin{abstract}
Özet: Bu çalışmada, jeotermal kaynak sularının, ahşabın hacimsel daralma ve genişleme özelliklerine (çalışma özelliği) karşı önleyici etkinliği araştırılmıştır. Bu amaçla, kızılçam (Pinus brutia Ten.) odunu örnekleri Türkiye'nin üç farklı jeotermal enerji sahasından (Afyonkarahisar, Denizli ve Kütahya) dokuz farklı jeotermal kaynak suyu ile batırma yöntemine göre muamele edilmiştir. Denizli'nin jeotermal kaynak suları ile muamele edilen odun örneklerinde genişleme ve daralmaya karşı daha yüksek bir performans gözlenmiştir. Ayrıca, işlem görmüş tüm ahşap numuneler, işlem görmeyenlere kıyasla daha düşük genişleme ve daralma değerlerine sahip olmuştur. Genişleme ve daralma değerlerindeki bu azalmalar, jeotermal kaynak sularının ahşabın hacimsel çalışma özelliğini azaltmada etkili olabileceklerini göstermektedir.

Anahtar kelimeler: Ahşap, Odun, Hacimsel çalışma, Jeotermal su, Boyutsal stabilite
\end{abstract}

\section{Preventive activity of geothermal resource waters against volumetric shrinkage and swelling properties of wooden}

\begin{abstract}
This study investigated the preventive effectiveness of geothermal resource waters on the volumetric shrinkage and swelling properties (working property) of wooden. For this purpose, Turkish red pine (Pinus brutia Ten.) wood samples were treated by immersion method with nine different geothermal source water from Turkey's three different geothermal fields (Afyonkarahisar, Denizli, Kütahya). A higher performance against shrinkage and swelling was observed in wood samples treated with Denizli's geothermal resource waters. Also, all treated wood samples had lower swelling and shrinkage values compared to untreated ones. These reductions in swelling and shrinkage values show that geothermal resource waters could be effective in reducing the volumetric working property of wooden.
\end{abstract}

Keywords: Wooden, Volumetric working, Geothermal water, Dimensional stabillity

\section{Giriş}

Ahşap üç farklı yönde çalışma (daralma-genişleme) özelliği nedeniyle boyutları değişebilen doğal bir malzemedir (Rindler vd., 2017). Bu özelliğini lif doygunluk noktası (LDN) rutubet içeriğine kadar gerçekleştirebilen ahşap LDN rutubeti altında su kaybederse daralır, fakat su alırsa genişler. Bu daralma ve genişleme, boyutsal değişimin yanında, yarılma, çatlama vb sakıncalı durumlara da neden olabilir (Ogunjobi vd., 2018). Bu nedenle ahşap, kullanımdan önce, çeşitli ön koruma işlemlerine tabi tutulur (Xie vd., 2013). Taghiyari vd. (2015), nanosüspansiyonlu gümüşoksit ve çinkooksit ile muamele edilen Paulownia odununda boyutsal değişikliğin azaldığını belirtmiştir. Bak vd. (2019), nanopartiküllü $\mathrm{SiO}_{2}$ işleminin kayın ve sarıçam odunlarında daralma ve genişlemeyi azalttığını ve boyutsal stabiliteyi iyileştirdiğini ifade etmiştir. Simsek vd. (2010) ise sodyumtetrafloroborat, amonyumtetrafloroborat ve amonyumpentaboratoktahidrat uygulamalarının kayın ve sarıçam odunlarında boyutsal değişim performansını iyileştirdiğini rapor etmiştir.
Günümüzde giderek artan çevresel duyarlılık ve bilinç, ahșap koruma ișlerinde su çözücülü ahșap emprenye maddelerinin kullanımını öncellemektedir (Lebow, 2010). $\mathrm{Bu}$ bağlamda, klasik su çözücülü ahşap emprenye maddelerinin formülasyonlarında da yer bulabilen fakl kimyasal/mineral içeren jeotermal enerji kaynakları da tartışılmalıdır. Bu doğal kaynaklardan Kütahya bölgesel jeotermal enerji kaynaklarının ahşap emprenye maddelerine katılan $\mathrm{Na}, \mathrm{K}, \mathrm{Ca}, \mathrm{B}, \mathrm{Mg}, \mathrm{Al}, \mathrm{F}, \mathrm{Cl}$ gibi farklı kimyasal madde ve mineral çeşitleri bakımından zengin oldukları belirtilmiștir (Var ve Kardaş, 2017). Bununla beraber, Demer ve Memiş (2015) tarafından Afyonkarahisar ÖmerGecek bölgesel jeotermal kaynaklarının $\mathrm{Na}-\mathrm{Cl}-\mathrm{HCO}_{3}$ tipli sular olduğu; bölgedeki Gazlıgöl jeotermal kaynağının yüksek $\mathrm{HCO}_{3}$ ve düşük $\mathrm{SO}_{4}$ içerdiği; ildeki tüm jeotermal enerji sahalarının yüksek derişimli $B$ ve $F$ içerdiği bildirilmiştir. Ayrıca Denizli bölgesel jetermal enerji kaynaklarının sülfatlı ve karbonatlı sular grubunda olduğu; bunların $\mathrm{Ca}, \mathrm{Cl}, \mathrm{Na}, \mathrm{K}, \mathrm{Mg}, \mathrm{HCO}_{3}, \mathrm{SO}_{4}$, klorürlü bileşikler, $\mathrm{CO}_{2}, \quad \mathrm{SiO}_{2}$ gibi çok farklı kimyasal/mineral maddeler içerdiği rapor edilmitir (Barut vd., 2013).

\footnotetext{
\ a Isparta Uygulamalı Bilimler Üniversitesi, Orman Fakültesi, Orman Endüstri Mühendisliği Bölümü, 32260, Isparta

b Emniyet Genel Müdürlüğü, Adana Emniyet Müdürlüğü, Yüreğir İlçe Emniyet Müdürlüğü, 01358, Yüreğir/Adana

@ * Corresponding author (İletişim yazarı): alivar@ isparta.edu.tr

$\checkmark \quad$ Received (Geliş tarihi): 06.07.2021, Accepted (Kabul tarihi): 07.12.2021
}

Citation (Atıf): Var, A.A., Yalçındağ, A., 2021 Jeotermal kaynak sularının ahşabın hacimsel daralma ve genişleme özelliklerine karşı önleyici etkinliği. Turkish Journal of Forestry, 22(4): 444448 . DOI: $10.18182 /$ tjf.962675 
Farklı sahalarda kullanımına yönelik pek çok çalışma bulunan jeotermal enerji kaynaklarının ahşabın çalışma özelliği üzerindeki boyutsal stabilite etkinliğine yönelik çalışmalar yok denecek kadar azdır. Bu düşünceden hareketle, bu makalede, jeotermal kaynak sularının kızılçam odununun daralma ve genişleme (çalışma özelliği) özelliklerine karşı önleyici etkilerinin araştırılması amaçlanmıştır. Araştırmadan beklenen sonuç, jeotermal kaynak sularının boyutsal stabilite etkisi yaparak odununun çalışma özelliğini azaltması yönündedir. Literatürdeki söz konusu bu eksiklikleri gidermeyi hedefleyen makale, ahşap teknolojisi çalışmalarına katkı sağlamak açısından önem arz etmektedir.

\section{Materyal ve yöntem}

Deneysel odun örnekleri, kızılçam (Pinus brutia Ten.) tomruğunun diri odun kısmından elde edilmiştir. $40 \mathrm{~mm} \times$ $50 \mathrm{~mm} \times 300 \mathrm{~mm}$ [Radial $(\mathrm{R}) \times \operatorname{Tangential}(\mathrm{T}) \times$ Longitudinal (L)] boyutlarında kesilen latalardan $20 \mathrm{~mm} \times$ $20 \mathrm{~mm} \times 30 \mathrm{~mm} \mathrm{~mm}$ ölçülerinde nümuneler hazırlanmıştır. Her test için, herhangi bir kusur içermeyen örneklerden tesadüfi-rastgele örnekleme yöntemiyle 10'ar adet numune seçilmiştir. $\mathrm{Bu}$ örnekler hava kurusu rutubete kadar kondisyonlanmış, etüvde $103 \pm 2^{\circ} \mathrm{C}^{\prime}$ de tam kuru (firın kurusu) rutubete kadar kurutulmuş ve desikatörde normal oda sicaklığına kadar soğutulmuştur (TS 2471, 1976). Sirasıyla, hava kurusu ve tam kuru rutubetlerdeki ölçümleri yapılan örneklerin muamele öncesi rutubet içerikleri firın kurusu duruma getirilmiştir.

Deneysel çalışma için Çizelge 1'de verilen jeotermal enerji sahaları ve jeotermal kaynak suları seçilmiştir. Seçimde en belirleyici unsur, bunların ciddi oranda ahşap emprenye maddesi formülasyonlarına katılan $\mathrm{B}, \mathrm{Na}, \mathrm{Ca}, \mathrm{K}$, $\mathrm{Mg}, \mathrm{Cl}, \mathrm{Al}, \mathrm{F}, \mathrm{S} \mathrm{O}_{4}, \mathrm{HCO}_{3}$ (Barut vd., 2013) gibi mineral tuzları içermeleri olmuştur. Bu kaynaklardan özel kaplara sıcak halde doldurulan jeotermal sular, normal çevre koşullarında herhangi bir işlem uygulanmadan oda sıcaklığına dek soğutulmuş, laboratuvara taşınmış ve pH değeri değişmeyecek şekilde depolanmıştır.

Odun örnekleri jeotermal sular ile laboratuvar şartlarında batırma yöntemine göre muamele edilmiştir (ASTM D1413-07e1, 2007). Bunun için numuneler öncelikle jeotermal su içerisine, üzerine ağırlık bırakılarak tamamen batırılmıştır. 24 saat sonra çıkarılan numunelerin üzerindeki jeotermal su fazlalığı-kalıntısı bir kâğıt havlu yardımıyla uzaklaştırılmıştır. Ardından, sırasıyla, brüt ağırlıkları ve boyutları ölçülmüştür. Daha sonra net ağırlıkları ve boyutları tekrar ölçülmeden önce, tüm numuneler etüvde $60 \pm 2^{\circ} \mathrm{C}^{\prime} \mathrm{de}$ tam kuru ağırlığa kadar kurutulmuş ve desikatörde oda sıcaklığına kadar soğutulmuştur (TS 2471, 1976). Her jeotermal su kaynağı için, bu işlemler tekrarlanmıştır.

Hacimsel çalışma özelliğini belirlemek için jeotermal kaynak suları ile muamele edilmiş ve edilmemiş odun örneklerinin hacimsel daralma ve genişleme değerleri ölçülmüştür. $\mathrm{Bu}$ amaçla, hacimsel daralma değerleri TS 4085 (1983)'e göre ölçülürken hacimsel genişleme değerleri TS 4086 (1983)'ya göre hesaplanmıştır. Boyuna yöndeki daralma ve genişlemeler dikkate alınmamıştır.

İstatistiksel analizlerde bilgisayar destekli istatistik programı, SPSS 20 Statistics, kullanılmıştır. Deneysel ölçümlerden edinilen tüm verilerin istatistiksel analizi \%95 güvenirlik $(\mathrm{p} \leq 0.05)$ düzeyinde varyans analizi (ANOVA) ile yapılmıştır. Gruplar (Ortalamalar) arasındaki istatistiksel karşılaştırmalarda Duncan testinden faydalanılmıştır.

\section{Bulgular ve tartışma}

\subsection{Hacimsel genişleme}

Şekil 1 ve Çizelge 2 jeotermal kaynak suları ile muamele edilmiş ve edilmemiş kızılçam odununun hacimsel genişleme özelliğine dair sonuçları göstermektedir.

Çizelge 1. Deneysel jeotermal enerji sahaları ve jeotermal su kaynakları

\begin{tabular}{|c|c|c|c|c|c|}
\hline \multirow{2}{*}{ Jeotermal enerji sahası } & \multicolumn{5}{|c|}{ Jeotermal su kaynağ1 } \\
\hline & Kaynak adı & Derinlik (m) & Sicaklık $\left({ }^{\circ} \mathrm{C}\right)$ & Debi (L/Sn) & $\mathrm{pH}$ \\
\hline \multirow{3}{*}{ Afyonkarahisar } & Gazlıgöl (GZL-1) & 138 & 66 & 2 & 7.4 \\
\hline & Gecek (R-260) & 165 & 92 & 1.5 & 7.5 \\
\hline & Ömer (AF-23) & 125 & 95 & 2.16 & 7.2 \\
\hline \multirow{3}{*}{ Denizli } & Gölemezli & - & 65 & 6 & 6.3 \\
\hline & İnaltı & - & 55 & 3 & 6.4 \\
\hline & Tekkeköy & - & 97 & 3 & 7.6 \\
\hline \multirow{3}{*}{ Kütahya } & Eynal & 220 & 96 & 3.5 & 8.2 \\
\hline & Çitgöl & 101 & 83 & 2.0 & 7.0 \\
\hline & Naşa & 200 & 64 & 2.0 & 6.6 \\
\hline
\end{tabular}




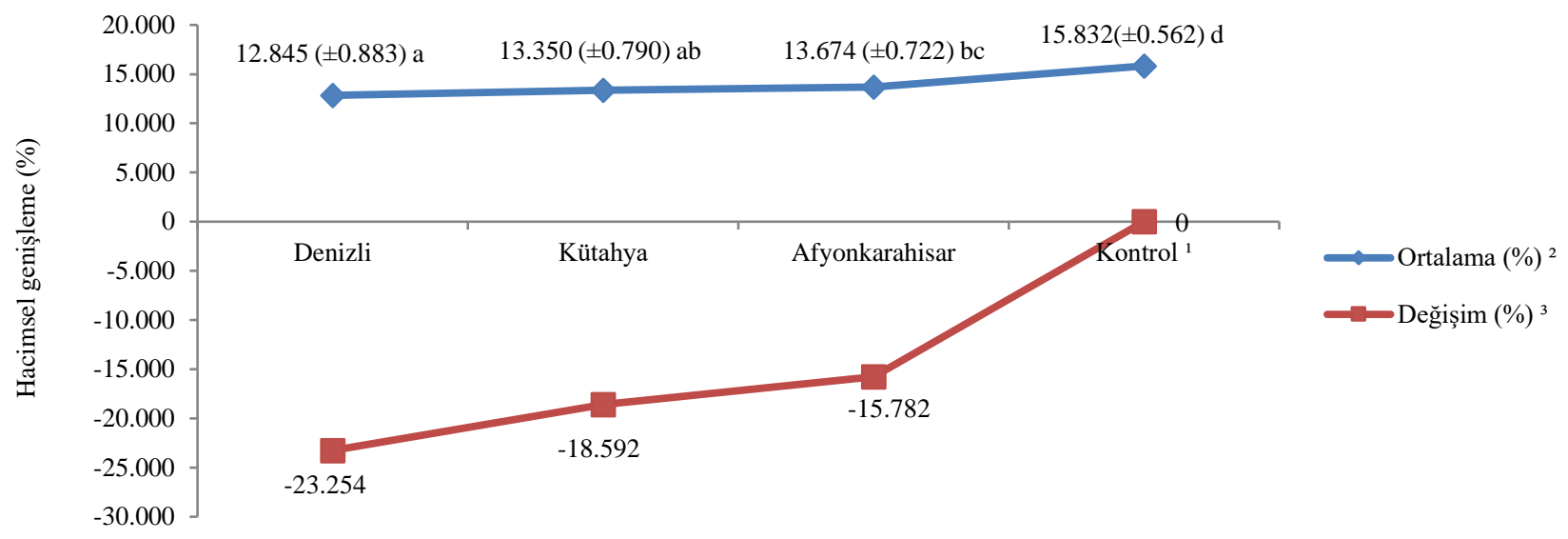

Jeotermal enerji sahas1

Şekil 1. Jeotermal enerji sahasına göre kızılçam odun örneklerinin hacimsel genişleme sonuçları ( ${ }^{1}$ Isşlem görmemiştir, ${ }_{2}$ Ayıraçtakiler standart sapmadır. Farklı harfle gösterilenler arasındaki fark anlamlıdır $(\mathrm{p} \leq 0,05),{ }^{3}$ Kontrole göre hesaplanmıştır.)

Çizelge 2. Jeotermal su kaynağına göre kızılçam odun örneklerinin hacimsel genişleme sonuçları

\begin{tabular}{lcc}
\hline Jeotermal su kaynağı & Ortalama $(\%)^{2}$ & Değişim $(\%)^{3}$ \\
\hline Tekkeköy & $12.244( \pm 0.739)$ ef & -29.304 \\
İnaltı & $12.650( \pm 0.553) \mathrm{fg}$ & -25.154 \\
Gölemezli & $12.678( \pm 0.487) \mathrm{fg}$ & -24.878 \\
Çitgöl & $12.907( \pm 0.389) \mathrm{fgh}$ & -22.662 \\
Eynal & $13.406( \pm 0.615) \mathrm{ghi}$ & -18.096 \\
Ömer & $13.614( \pm 0.801) \mathrm{ijk}$ & -16.292 \\
Naşa & $13.993( \pm 0.565) \mathrm{ij}$ & -13.142 \\
Gazlıgöl & $14.025( \pm 0.410) \mathrm{ij}$ & -12.884 \\
Gecek & $14.091( \pm 0.613) \mathrm{ij}$ & -12.355 \\
Kontrol ${ }^{1}$ & $15.832( \pm 0.562) \mathrm{k}$ & 0 \\
\hline${ }^{1}$ İşlem görmemiştir. ${ }^{2}$ Ayıraçtakiler standart sapmadır. Farklı harfle gösterilenler \\
arasındaki fark anlamlıdır $(\mathrm{p} \leq 0,05) .{ }^{3}$ Kontrole göre hesaplanmıştır.
\end{tabular}

Şekil 1 ve Çizelge 2 sonuçlarına göre, jeotermal kaynak suları ile işlem gören örneklerin hacimsel genişleme değerleri hem jeotermal enerji sahaları için hem de jeotermal kaynak suları için istatistiksel açıdan önemli ölçüde azalmıştır. Buna ilaveten, İnaltı ve Gölemezli muamelelerinde ölçülen hacimsel genişleme değerleri arasında önemli bir farlılık olmadığı; benzer sonuçların Naşa, Gazlıgöl ve Gecek muamelelerinde de elde edildiği ortaya çıkmıştır (Çizelge 2). Denizli jeotermal sahası için, işlem görmüş örneklerin hacimsel genişleme miktarları birbirine yakın bulunmuş, işlem görmemiş örneklere kıyasla \%23.254 oranında daha düşük bir hacimsel genişleme miktarı tespit edilmiştir (Şekil 1). Bunun anlamı; Denizli jeotermal kaynak suları odunun hacimsel genişleme özelliğini muamele edilmeyenlere göre \%24.878 - \%29.304 oranında daha fazla azaltmıştır. Bu oran diğer jeotermal kaynak suları için \%12.355 - \%22.662 arasında kalmıştır (Çizelge 2).

Tüm bu sonuçlar, farklı mineral maddeler içeren jeotermal kaynak suyunun odunun hacimsel genişleme özelliğini azalttığını göstermiştir. Buna ilaveten, muhtemelen hücre çeperi çukurlarına ve gözeneklerine de giren bu mineraller toplam hacimsel genişlemeyi daha fazla bloke etmiş olabilir. Ayrıca hücre boşluklarını dolduran ve hücre çeperlerinde tabaka oluşturan jeotermik mineraller buralarda da ilaveten bir genişleme karşıtı etkiler yapmış olabilir. Bu etkiye bağlı olarak muamele görmüș örneklerin hacimsel genişlemesi muamele görmemişlere kıyasla biraz daha düşük olabilir. Diğer yandan, hacimsel genişlemenin azalması, jeotermal su kaynaklarındaki anyonik ve katyonik maddelerin/minerallerin bileşik etkisiyle de açıklanabilir. Yani; azalan hacimsel genişleme hücre çeperi yüzeylerine dağılan jeotermik maddelerin odunun hacimsel genişleme özelliğini azalttığı anlamına gelmektir.

Çetin ve Gündüz (2016), kızılçam odun örneklerinin hacimsel genişleme değerlerinin \%10.8'den \%15.5'e kadar değiştiğini göstermiştir. Bu çalışmamızda ise elde edilen söz konusu değerler \%12.24 - \%14.09 arasında değişmiştir. Bununla beraber, Bak vd. (2019), hidrofobik $\mathrm{SiO}_{2}$ nanopartikülleriyle işlem gören odunlar için hacimsel genişlemenin önemli ölçüde azaldığ sonucuna yer vermiştir. Ayrıca, odunda polimerleşen kimyasal maddelerin hücre çeperi yüzeyini kaplayarak pürüzlü bir tabaka oluşturduğu (Dong vd., 2015), yüzeyin serbest enerjisini azaltan bu pürüzlü tabakanın kendi su iticiliğini geliștirdiği rapor edilmiştir (Bak vd., 2019). Bu durumda Şekil 1 ve Çizelge 2'deki sonuçların literatür bulgularıyla tutarlı olduğu açıktır.

\subsection{Hacimsel daralma}

Şekil 2 ve Çizelge 3 jeotermal kaynak sularıyla muamele edilmiş ve edilmemiş kızılçam odun örneklerinin hacimsel daralma sonuçlarını göstermektedir. 


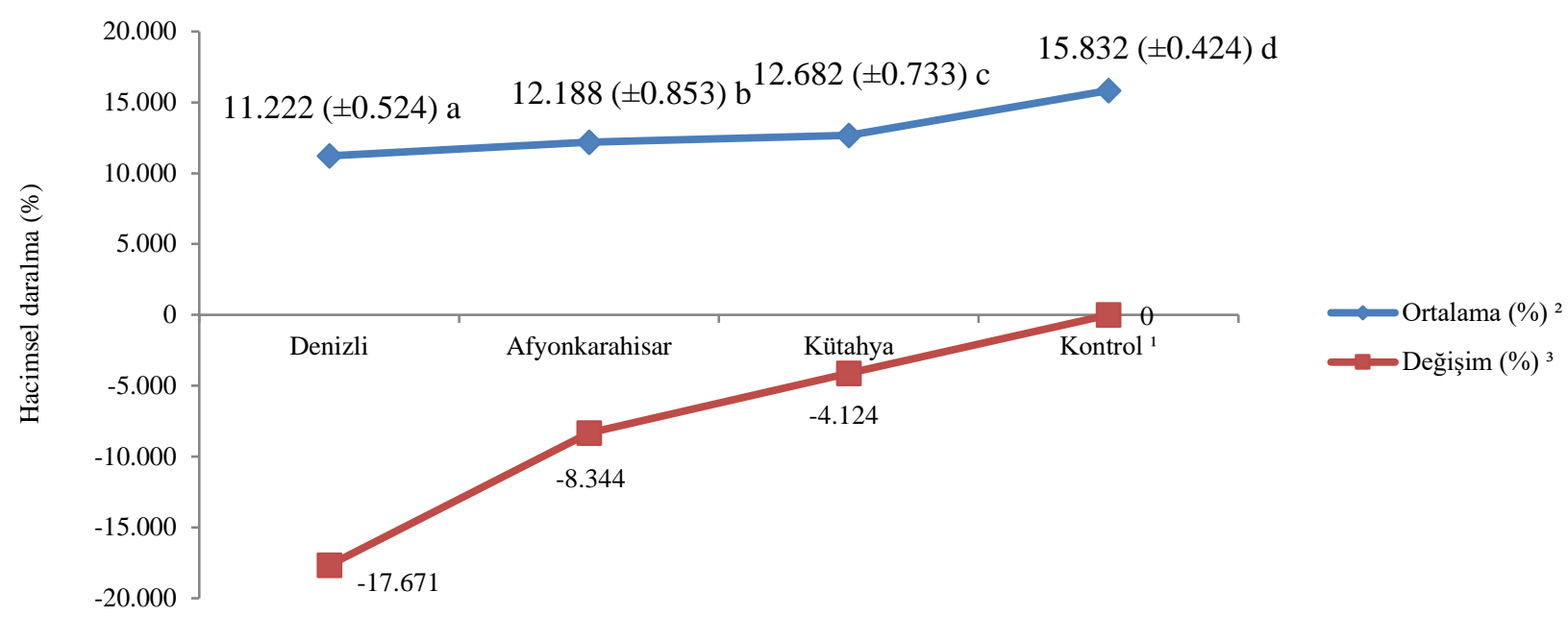

Jeotermal enerji sahası

Şekil 2. Jeotermal enerji sahasına göre kızılçam odun örneklerinin hacimsel daralma sonuçları $\left({ }^{1}\right.$ İşlem görmemiştir. ${ }^{2}$ Ayıraçtakiler standart sapmadır. Farklı harfle gösterilenler arasındaki fark anlamlıdır $(\mathrm{p} \leq 0,05)$. ${ }^{3}$ Kontrole göre hesaplanmıştır.)

Şekil 2 sonuçlarına göre, en küçük hacimsel daralma Denizli jeotermal enerji sahası için \%11.222 olarak ölçülürken, en büyük hacimsel daralma Kütahya bölgesi için $\% 12.682$ olarak ölçülmüştür. Çizelge 3 sonuçları, hesaplanan hacimsel daralmanın Tekkeköy muamelesi için en düşük (\%11.164) olurken, Naşa muamelesi için en yüksek (\%13.193) olduğunu ortaya koymuştur. Bu sonuçlar, farklı jeotermal enerji sahaları için uygulanan jeotermal kaynak suyu muamelelerinin, odun örneklerinin hacimsel daralma davranışını etkileyerek azaltabileceği anlamına gelmektedir. Yani; odunun hacimsel daralması uygulanan jeotermal suyu işlemleri ile bir miktar düşmüştür. Diğer bir deyişle, jeotermal kaynak suyu uygulamasını takiben damitık suda 24 saat bekletilen odunda hacimsel daralmayı önleyici performans artmıştır. Bu anlamda, en iyi sonucu, sahalar bazında Denizli jeotermal enerji sahası verirken (Şekil 2), kaynaklar bazında Tekkeköy jeotermal su kaynağı vermiştir (Çizelge 3).

Şekil 2 ve Çizelge 3'de, uygulanan jeotermal kaynak suyu işlemlerinin etkisinin bir sonucu olarak, işlem gören odun örnekleri için belli bir düzeyde hacimsel daralma azalması görülmektedir. Bu değişen hacimsel daralma, Denizli, Afyonkarahisar ve Kütahya jeotermal enerji sahaları için \%4.124-\%17.671 arasında iken (Şekil 2), jeotermal su kaynakları için \%2.867-\%18.282 arasında değişmiştir (Çizelge 3). Çizelge 3 sonuçları göstermiştir ki, en düşük hacimsel daralma miktarları Tekkeköy, İnaltı ve Gölemezli kaynaklarında gözlenmiştir. $\mathrm{Bu}$ azalma (değişim), işlem görmeyen kontrol örneklerine kıyasla \% 17.045 ile \% 18.282 oranlarında seyretmiştir. Bu bakımdan, Tekkeköy muamelesi ile İnaltı (\%17.681) ve Gölemezli (\%17.045) muameleri arasinda istatistiksel anlamda benzerlik gözlenmiştir. Bu benzerliği Gecek, Çitgöl ve Ömer muameleleri de göstermiştir.
Çizelge 3. Jeotermal su kaynağına göre kızılçam odun örneklerinin hacimsel daralma sonuçları

\begin{tabular}{|c|c|c|}
\hline Jeotermal su kaynağ1 & Ortalama $(\%)^{2}$ & Değişim $(\%)^{3}$ \\
\hline Tekkeköy & $11.164( \pm 0.557) \mathrm{e}$ & -18.282 \\
\hline İnaltı & $11.221( \pm 0.401) \mathrm{e}$ & -17.681 \\
\hline Gölemezli & $11.282( \pm 0.636) \mathrm{e}$ & -17.045 \\
\hline Gecek & $11.943( \pm 0.382) \mathrm{f}$ & -10.567 \\
\hline Çitgöl & $12.017( \pm 0.500) \mathrm{f}$ & -9.886 \\
\hline Ömer & $12.187( \pm 0.550) \mathrm{f}$ & -8.353 \\
\hline Gazlıgöl & $12.435( \pm 0.491) \mathrm{fg}$ & -6.192 \\
\hline Eynal & $12.837( \pm 0.539) \mathrm{gi}$ & -2.867 \\
\hline Naşa & $13.193( \pm 0.618) \mathrm{i}$ & -0.091 \\
\hline Kontrol $^{1}$ & $13.205( \pm 0.424) \mathrm{i}$ & 0 \\
\hline
\end{tabular}

$\mathrm{Bu}$ sonuçlara göre azalan hacimsel daralma, değişen selülozik yap1 ve yumuşayan odunsu hücrelerle ilişkili olabilir. İşlem gören odunun selülozik sistemi ve odunsu hücreleri jeotermal su buharlaştıktan sonra daha az daralabilir. Odunsu hücreler jeotermal sularla işlem sırasında yumuşayabilir. Böyle yumuşayan hücrelerin esnekliği, jeotermal suyun buharlaşmasıyla azalabilir. Fileksibilitesi azalan odunsu hücreler, daha esnek hücreleri kendine çektiği için genel bir hacimsel daralma olabilir. Bu olayın doğal bir sonucu olarak daha fazla daralma gerçekleşebilir. Birkaç çalışmada, amonyak ve türevleriyle muameleden sonra, çözücülerin hücre, lümen ve çeper sistemlerinden buharlaşırken odunsu hücrelerin yumuşaklığının azaldığı, yumuşaklığını yitiren hücrelerin daha yumuşak hücreleri kendine doğru çektiği, bunun sonunda da daralmanın daha fazla olduğu bildirilmiştir (Stamm, 1955; Pentoney, 1966; Bariska, 1975). Ayrica bu durum (hacimsel daralma azalması), jeotermal mineral retensiyonu ile de ilişkili olabilir. Retense mineraller hücre çeperi sistemlerini tıkayabilir, bu tıkalı sistemler hacimsel daralmayı azaltabilir. Tüm bunlar, jeotermal su muamelesi gören odunun absorbe ettiği anyonik ve katyonik minerallerin odunun hacimsel daralma eğilimini kısıtladığ sonucuna götürmüştür. 
Bozkurt vd. (1993), mineral maddelerle işlem gören ahşabın daralma değerinin, işlem görmeyen ahşaba göre daha düşük olduğunu kaydetmiştir. Coles ve Walker (1978), absorbe edilen minerallerin odunun su alma kapasitesini azalttığını, bu azalmanın odunun daralma önleyici performansını iyileştirdiğini rapor etmiştir. Bazı araştırmacılar jeotermal kaynak sularında da bulunan, amonyak (Coles ve Walker, 1978), siv1 amonyak (Pollisco vd., 1971) ve amonyak buharı/gazı (Stamm ve Seborg, 1936) gibi, amonyak ve türevlerinin oduna azalan bir hacimsel daralma niteliği kazandırdığını kaydetmiştir. Bu durumda, jeotermal kaynak suyu muamelesinin kızılçam odununun hacimsel daralma değerini düşürdüğünü ortaya koyan Şekil 2 ve Çizelge 3'deki bulguların literatür sonuçları ile uyumlu olduğu söylenebilir.

\section{Sonuç}

Jeotermal enerji kaynakları çok farklı alanlarda kullanılmaktadır. Ahşap kullanımında öne çıkan önemli kriterlerden birisi de hacimsel çalışmadır (daralmagenişlemedir). Bu makalede, Ege Bölgesinden bazı jeotermal kaynak suları ile muamele edilen kızılçam odununun hacimsel daralma ve genişleme özellikleri üzerinde durulmuştur.

$\mathrm{Bu}$ araştırmada kullanılan tüm jeotermal enerji sahaları ve kaynak suları için, jeotermal muameleler sonunda, işlem gören odun örneklerinin hacimsel genişleme ve daralma değerleri işlem görmeyenlere kıyasla bir miktar azalmıştır. Değişen azalma önleyici etkinlik derecesi jeotermal su kaynaklarına veya bunların kimyasal/mineral içerik farklılığına bağlı olabilir.

Azalan hacimsel çalışma, jeotermal enerji sahaları bazında, genişleme ve daralma için, sırasıyla, \%15.782 $\% 23.254$ ve $\% 4.124$ - \%17.671 aralığında değişmiştir. Genellikle hacimsel çalışmanın en düşük olduğu lokasyon Denizli jeotermal enerji sahası olmuştur. En düşük hacimsel daralma miktarları Tekkeköy, İnaltı ve Gölemezli kaynaklarında gözlenmiştir Tüm sahalar dikkate alındığında, hacimsel çalışmayı azaltma noktasında, Denizli jeotermal su kaynaklarının daha uygun olduğu sonucuna varılabilir.

Tüm bunlardan, jeotermal kaynak sularıyla işlem gören odunun boyutsal stabilite etkinliğine sahip olduğu sonucu çıkarılabilir. Bu etkinlik, seçilen jeotermal su kaynaklarının, odunun hücre çeperi sistemlerine penetre ve/veya retense olabilen farklı anyonik ve katyonik mineral içermeleri ile açıklanabilir. Mineral penetrasyonu ve/veya retensiyonu hücre çeperi sistemlerini tıkamakla beraber bu sistemlerin esnekliğini de azaltabilir. Azalan esneklik, tüm hacimsel davranışı kısıtladığı için odunun boyutsal stabilitesini iyileştirebilir. Böyle minerallerin, hacimsel çalışmaya karşı, işlem görmüş odunu işlem görmemiş odundan daha etkin hale getirdiği açıktır. Kalıcı ve uzun süreli bir boyutsal stabilite etkinliği, yeterli mineral penetrasyonu ve retensiyonu ile ancak mümkün olabilir.

\section{Kaynaklar}

ASTM D1413-07e1, 2007. Standard test method for wood preservatives by laboratory soil block cultures. Annual Book of ASTM Standarts, West Conshohocken, PA, USA.

Bak, M., Molnár, F., Németh, R., 2019. Improvement of dimensional stability of wood by silica nanoparticles, Wood Material Science \& Engineering, 14 (1): 48-58.
Bariska, M., 1975. Collapse phenomena in beechwood during and after $\mathrm{NH}_{3}$-impregnation. Wood Sci. and Technol., 9: 293-306. Https://link.springer.com/article/10.1007/BF00353479, Erișim: 25.02.2021

Barut, İ.F., Erdoğan, N., Erol, B.B., Güneri, F.D., 2013. Evaluation from past to present hydrochemical characteristics with use of thermal mineral waters of Denizli. Istanbul Journal of Earth Sciences, 26(1): 1-24. https://dergipark.org.tr/tr/download/ articlefile/763591, Erișim: 15.01.2021.

Bozkurt, A.Y., Goker, Y., Erdin, N., 1993. Emprenye Tekniği Ders Notları. Istanbul Univ. Orman Fakültesi yayınları, Istanbul.

Coles R.W., Walker J.C.F., 1978. Induced shrinkage and structural reorganisation in ammonia-treated wood of Corsican pine. Wood and Fiber, 10(1): 39-57.

Çetin, F., Gündüz, G., 2016. Evaluation of research studies about physical properties of some wood species in Turkey. Journal of Bartin Faculty of Forestry, 18(2): 175-193. DOI: 10.24011/barofd.267294

Demer, S., Memiş, Ü., 2015. Hydrogeochemistry and geothermometer applications to Afyonkarahisar geothermal fields. SDU Journal of Natural and Applied Science, 19(2): 66-77. https://dergipark.org.tr/tr/download/article-file/194064, Erișim: 25.12.2020.

Dong, Y., Yan, Y., Zhang, S., Li, J., Wang, J., 2015. Flammability and physical-mechanical properties assesment of wood treated with furfuryl alcohol and nano- $\mathrm{SiO}_{2}$. European J. of Wood and Wood Products, 73(4): 457-464. DOI: 10.1007/s00107-015-0896-y

TS 2471, 1976. Wood - Determination of moisture content for physical and machenical tests. TSE, Ankara.

TS 4085, 1983. Wood - Determination of volumetric shrinkage. TSE, Ankara.

TS 4086, 1983. Wood - Determination of volumetric swelling. TSE, Ankara

Lebow, S.T., 2010. Wood preservation wood handbook: Wood as an engineering material: Chapter 15. Centennial ed. General technical report FPL; GTR-190. Madison, WI: U.S. Dept. of Agriculture, Forest Service, Forest Products Laboratory, pp. 15.1-15.28.

Ogunjobi, K.M., Ogundibo D.E, Adetogun A.C. and Omole A.O., 2018. Variation in anisotropic shrinkage of plantation-grown Tectona Grandis (Linn) wood. Journal of Research in Forestry, $\begin{array}{lll}\text { Wildlife \& } \quad \text { Environment, } & 10(2): & 85-90 .\end{array}$ https://www.ajol.info/index.php/jrfwe/article/view/174799, Erişim: 10.10.2020.

Pentoney, R.E., 1966. Liquid ammonia-solvent combinations in wood plasticization. Properties of treated wood. Ind.Eng.Chem.Prod.Res.Dev., 5(2): 105-110.

Pollisco, F.S., Skaar, C., Davidson, R.W., 1971. Some physicial properties of maple wood treated with ammonia vapor. Wood Sciences, 4/2: 65-70.

Rindler, A., Vay, O., Hansmann, C., Muller, U., 2017. Dimensional stability of multi-layered wood-based panels: a review. Wood Sci. Technol., 51: 969-996. DOI: 10.1007/s00226-017-0940-7

Simsek, H., Baysal, E., Peker, H., 2010. Some mechanical properties and decay resistance of wood impregnated with environmentallyfriendly borates. Construction and Building Materials 24(11): 2279-2284. DOI: 10.1016/j.conbuildmat.2010.04.028

Stamm, A.J., Seborg, R.M., 1936. Minimizing wood shrinkage and swelling: Treating with synthetic resin-forming materials. Ind. Eng. Chem., 28 (10): 1165-1169.

Stamm, A. J., 1955. Swelling of wood and fiberboards in liquid ammonia. Forest Products Journal, 5(6): 413-416.

Taghiyari, H.R., Kalantari, A., Ghorbani, M., Bavaneghi, F., Akhtari, M., 2015. Effects of fungal exposure on air and liquid permeability of nanosilverand nanozincoxide-impregnated Paulownia wood. International Biodeterioration \& Biodegradation, 105: 51-57. DOI: 10.1016/j.ibiod.2015.08.014.

Var, A.A., Kardaş, İ., 2017. Modulus of rupture, compression strength parallel to grain and static quality value of pine wood treated with geothermal waters from Simav region of Turkey. J. of Bartin Faculty of Forestry, 19(1): 93-101. DOI: 10.24011/barofd.295682

Xie, Y., Fu, Q., Wang, Q., Xiao, Z., Militz, H., 2013. Effects of chemical modification on the mechanical properties of wood. Eur. J. Wood Prod., 71: 401-416. DOI: 10.1007/s00107-013-06. 